\title{
The efficacy of transversus abdominis plane block for post-operative analgesia after the cesarean section performed under general anesthesia
}

\author{
(1) Halil Buluc, ${ }^{1}$ (1) Arzu Yildirim Ar, ${ }^{1}$ (1) Guldem Turan, ${ }^{1}$ (i) Firdevs Karadogan, ${ }^{2}$ (i) Mehmet Akif Sargin, ${ }^{3}$ \\ (iD Nur Akgun ${ }^{1}$ \\ ${ }^{1}$ Department of Anesthesiology and ICU, Fatih Sultan Mehmet Training and Research Hospital, Istanbul, Turkey \\ ${ }^{2}$ Department of Anesthesiology and ICU, Kepez State Hospital, Antalya, Turkey \\ ${ }^{3}$ Department of Gynocology, Fatih Sultan Mehmet Training and Research Hospital, Istanbul, Turkey
}

\begin{abstract}
OBJECTIVE: Several methods are used to control the pain after cesarean operations. Recently, the transverse abdominis plane block (TAP) has been proposed to compensate for the problems developed by preexisting methods. In the present study, we compared the analgesic efficacy of the TAP block after caesarean section in a prospective, randomized, doubleblinded controlled trial.

METHODS: In this study, thirty patients undergoing cesarean sections under general anesthesia were divided into two groups. Patients in Group T $(n=15)$ on whom TAP Block with USG guidance was performed using $0.25 \%$ bupivacaine totally $60 \mathrm{ml}$. The patients in Group C were administered $(n=15), 0.9 \% \mathrm{NaCl}$ totally $60 \mathrm{ml}(30 \mathrm{ml}$ at each side) with USG guidance. Post-operative demand of meperidine using a patient-controlled analgesia device was recorded.

RESULTS: First time on the need for analgesia were significantly higher in the control group (Group C). The total dose of meperidine, tenoxicam, paracetamol used for analgesia was significantly higher in the Group $\mathrm{C}$. The outset times of breastfeeding and mobilization did not change between the groups.

CONCLUSION: The USG-TAP block with $0.25 \%$ bupivacaine $60 \mathrm{ml}$ (30 ml on each side) significantly reduced post-operative pain in patients undergoing the cesarean section. We think that TAP block is a comfortable and feasible method which reduces post-operative analgesia need and does not lead any serious complications.
\end{abstract}

Keywords: Bupivacaine; cesarean section; post-operative pain; transverse abdominis plane block; ultrasound.

Cite this article as: Buluc H, Yıldırım Ar A, Turan G, Karadagan F, Sargin MA, Akgun N. The efficacy of transversus abdominis plane block for postoperative analgesia after cesarean section performed under general anesthesia. North Clin Istanb 2019;6(4):368-373.

$\mathrm{P}$ ost-operative pain has been one of the main interests of anesthesiologists because of reducing patients comfort and it is potential for causing harmful effects since the beginning of practice. Cesarean section is one of the most commonly performed surgical procedures. It is estimated that $15 \%$ of the births worldwide and $21.1 \%$ of the births in the developed world occur by cesarean section [1]. Inadequate post-operative pain relief after the cesarean section may negatively affect mobilization, breastfeeding, and even the emotional bond between the mother and the infant, while effective analgesia improves the amount of breastfeeding and infant weight gain $[2,3]$. Different methods are used for post-operative pain management during 24 hours in the

Received: May 07, 2017 Accepted: December 28, 2018 Online: March 10, 2019

Correspondence: Dr. Guldem TURAN. Fatih Sultan Mehmet Egitim ve Arastirma Hastanesi, Bostancı, Istanbul, Turkey.

Tel: +905332161576 e-mail: gturanmd@yahoo.com

(c) Copyright 2019 by Istanbul Provincial Directorate of Health - Available online at www.northclinist.com 
cesarean section $[4,5]$ The optimum form of post-operative analgesia is not known.

Rafi first described the TAP block in 2001 [6]. He portrayed TAP block as a refined abdominal field block, with a targeted single shot anesthetic delivery into the TAP, a site which relevant nerve branches are located. Even though it has been just a decade since its discovery, TAP block has been used in several types of surgical procedures with various modifications. TAP block has been shown to be effective in the cesarean section and after hysterectomy, open prostatectomy, laparoscopic cholecystectomy, and appendectomy $[7,8]$. In this study, we aimed to evaluate the postoperative analgesic efficacy of the TAP block in patients who are having a cesarean section under general anesthesia.

\section{MATERIALS AND METHODS}

In this study, following institutional Ethics Committee approval (No:2015-56,1707317) and informed patient consent, patients undergoing a cesarean section were chosen with randomized double-blinded by closed-loop envelope technique. Thirty ASA I-II patients undergoing elective cesarean section were included in our study. Exclusion criteria were blood coagulation pathologies, allergies against amino-amide local anaesthetics, or inability to understand the study protocol.

No premedication was used before the operation, administration of $\mathrm{NaCl} 0.9 \%$ solution via peripheral venous access was started. Standard monitoring (pulse oximetry, electrocardiogram, and non-invasive arterial pressure) was performed, and general anaesthesia was induced with propofol $2-2.5 \mathrm{mg} / \mathrm{kg}$ and rocuronium $0.6 \mathrm{mg} / \mathrm{kg}$. Subsequently, the trachea was intubated, and general anaesthesia was continued with $1 \mathrm{MAC}$ sevoflurane in $50 \%$ air $/ \mathrm{O}_{2}$. The lungs were mechanically ventilated using a pressure-controlled mode to maintain Et $\mathrm{CO}_{2}$ between 4.7 and $5.3 \mathrm{kPa}$.

Patients were divided with double-blinded technique into two groups before the induction of anesthesia; both groups were visuilazed with ultrasound (Famio 8, Toshiba Ootawarashi, Japan) at the end of the surgery before the recovery from anesthesia. The probe was placed in the area between costal margin, iliac crest and midaxillary line. Once the external oblique abdominis muscle (EOAM), internal oblique abdominis muscle (IOAM) and transversus abdominis muscle (TAM) were visualized at the level of the anterior axillary line between the $12^{\text {th }}$ rib and the iliac crest (Fig. 1), the puncture area and the ultrasound probe were prepared in a sterile manner. Then, the block was performed with a 0.91x100 mm, 20 Gauge (Stimuplex D Braun) needle and an injection line realizing an 'in-plane' ultrasoundguided technique as illustrated in Figure 1. Once the tip of the needle was placed in the space between the IOAM and TAM and negative aspiration. After negative aspiration $2 \mathrm{ml}$ of $\mathrm{NaCl} 0,9 \%$ was administered between I.O.M and T.A.M to verify the location of the needle. In

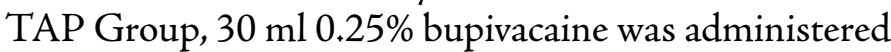
under direct ultrasonographic guidance. The contralateral block was performed equally. In the control group, $30 \mathrm{ml} \mathrm{NaCl} 0.9 \%$ was administered between I.O.M. and T.A.M. at both sides.

During operations, heart rates and systolic/diastolic mean arterial pressures were recorded at 15 min time intervals. Before the end of the surgery, all patients were administered $1 \mathrm{mg} / \mathrm{kg}$ meperidine I.V bolus for analgesia. After the end of the operation at the time of $0,5,15$, 30. minutes and $1,2,4,12$. ve 24 . hours pain score has been rated with a visual analog scale (VAS) and verbal descriptor scales (VDS). Sedation level has been evaluated using a modified Ramsay scale. Nausea, vomiting mobilization time, breastfeeding time, patient satisfaction and duration of surgery were also recorded.

After the operation, the patients were transferred to the recovery room, where the analgesia was maintained using patient-controlled analgesia (PCA). The correct use of the device was precisely explained during the patient's informed consent. The patients stayed for $2 \mathrm{~h}$ in the recovery room and were then transferred to the ward.



FIGURE 1. Ultrasound image during initial injection, image of the needle and the muscle layers. 
During the $2 \mathrm{~h}$ in the recovery room and subsequent 24 $\mathrm{h}$ on the ward, the total amount of meperidine administration was recorded.

All the patients were attached to the PCA pump, including meperidine $10 \mathrm{mg}$ meperidine bolus and 15 minutes of lockout time aiming post-operative analgesia control. Instead of using PCA, if VAS score still remains bigger than three (VAS $>3) 1$ gr paracetamol I.V was administered. If VAS score still remains bigger than three (VAS $>3$ ) tenoxicam $20 \mathrm{mg}$ I.V was administered to the patient. If VAS score still remains bigger than three (VAS $>3$ ) $0.5 \mathrm{mg} / \mathrm{kg}$ meperidine IV has been given to the patient as the last option. During 24 hours in both groups, the need for analgesia has been compared. Twenty-four hours after the injection, both sites of the TAP block injections were inspected to detect side-effects such as haematomas or infection.

When evaluating the results obtained in this study, IBM SPSS Statistics 22 program was used for statistical analysis. We used the Shapiro Wilks test when evaluating distribution suitability of the parameters. Data were presented as mean (SD), number (\%), or ratio as appropriate. After testing for normal distribution were compared with Student's t-test, and groups with a normal distribution were compared using a Mann-Whitney U-test. A paired sample t-test was used for intra-group comparison of quantitative data showing a normal distribution, and Wilcoxon Signed Ranks test was used for intra-group comparison of parameters without normal distribution. Fisher's exact test was used during the comparison of qualitative data. P-values of 0.05 were considered significant.

\section{RESULTS}

With 15 patients per group, a total of 30 patients were entered into this study. There was no statistically signifcant difference among two groups regarding age, weight, height, body mass index (BMI), ASA physical status and additional diseases, such as hypertension, diabetes mellitus or history of abdominal surgery, and operation time (Table 1).

There was no statistical difference in mean arterial pressures between the two groups. In group T, according to baseline, there was no significant change after induction $1^{\text {st }}, 5^{\text {th }}$ and $10^{\text {th }}$ minute. The decrease in the 1 st minute was significant $(p=0.017)$. There was a significant decrease in all post-operative measurement times compared to baseline $(p<0.05, p<0.01)$. In group $C$, according to baseline, there was a significant decrease in all post-operative measurement times $(p<0.05, p<0.01)$.

In TAP Group, no patient needed extra analgesic requirements. However, in the control group, 11 patient needed extra tenoxicam $20 \mathrm{mg}$ 1.v bolus for analgesia requirement. Among these 11 patients who were administered extra paracetamol, six of them needed $1 \mathrm{gr}$ paracetamol 1.v for further analgesia, and finally, among these six patients, three of them needed $50 \mathrm{mg}$ meperidine bolus for further analgesia.

VAS in group, $\mathrm{C}$ was significantly higher than the TAP group at post-operative $1 ., 5$. and 15 . minutes. $(p=0.001$; $p<0.01)(p=0.004 ; p<0.01)(p=0.012 ; p<0.05)$. There was no difference in the further time periods. In group $\mathrm{T}$, according to post-operative $1^{\text {st }}$ minute, there was a significant decrease after $15^{\text {th }}$ minute post-operative measurement times $(p<0.05, p<0.01)$. In group $C$, there was a sig-

TABLE 1. Evaluation of the demographic characteristics between the groups

\begin{tabular}{|c|c|c|c|c|}
\hline & $\begin{array}{c}\text { TAP Group } \\
\text { Median } \pm S D\end{array}$ & $\begin{array}{c}\text { Control Group } \\
\text { Median } \pm S D\end{array}$ & $\begin{array}{c}\text { Total } \\
\text { Median } \pm S D\end{array}$ & $\mathrm{p}$ \\
\hline Age (year) & $30.27 \pm 4.79$ & $28.8 \pm 4.13$ & $29.53 \pm 4.45$ & ${ }^{1} 0.376$ \\
\hline BMI $\left(\mathrm{kg} / \mathrm{m}^{2}\right)$ & $30.08 \pm 4.16$ & $30.62 \pm 6.4$ & $30.35 \pm 5.31$ & ${ }^{1} 0.786$ \\
\hline Operation time (min) & $50.2 \pm 11.72$ & $38.0 \pm 10.82$ & $44.1 \pm 12.7$ & ${ }^{1} 0.006 * *$ \\
\hline \multicolumn{5}{|l|}{ ASA, n (\%) } \\
\hline 2 & $4(26.7)$ & $3(20)$ & $7(23.3)$ & \\
\hline Additional diseases n (\%) & $4(26.7)$ & $3(20)$ & $7(23.3)$ & ${ }^{2} 1.000$ \\
\hline
\end{tabular}

${ }^{1}$ Student's t-Test; ${ }^{2}$ Fisher's Exact Test; ${ }^{* *} \mathrm{p}<0.01$; SD: Standard deviation. 
nificant decrease in all post-operative measurement times compared to postoperative $1^{\text {st }}$ minute $(\mathrm{p}<0.01)$ (Table 2$)$.

VDS in group $C$ is significantly higher than group $T$ at post-operative $1,5,15,30,60$. minutes. $(p=0.001$; $\mathrm{p}<0.01) \quad(\mathrm{p}=0.001 ; \quad \mathrm{p}<0.01) \quad(\mathrm{p}=0.012 ; \mathrm{p}<0.05)$ $(p=0.001 ; p<0.01)(p=0.047 ; p<0.05)$. There was no difference in the further time periods. In group $\mathrm{T}$, there was

\section{TABLE2. Visual Analog Scale (VAS) Variation}

\begin{tabular}{|c|c|c|c|}
\hline VAS & $\begin{array}{c}\text { Group T } \\
\text { Mean } \pm \text { SD } \\
\text { (Median) }\end{array}$ & $\begin{array}{c}\text { Group C } \\
\text { Mean } \pm \text { SD } \\
\text { (Median) }\end{array}$ & $\mathrm{p}$ \\
\hline Postop $1^{\text {st }} \min$ & $2.27 \pm 0.88$ (3) & $5.2 \pm 1.82(6)$ & $0.001 * *$ \\
\hline Postop $5^{\text {th }} \min$ & $2.27 \pm 0.88(3)$ & $4.13 \pm 1.88(3) \neq$ & $0.004 * *$ \\
\hline Postop $15^{\text {th }} \min$ & $1.93 \pm 1.1(2) \dagger$ & $3.33 \pm 1.59(3) \neq$ & $0.012 *$ \\
\hline Postop $30^{\text {th }}$ min & $1.93 \pm 1.1(2) \dagger$ & $2.53 \pm 0.83(3) \neq$ & 0.096 \\
\hline Postop $1^{\text {st }} \mathrm{hr}$ & $1.8 \pm 1.01(2) \neq$ & $2.07 \pm 1.44(2) \neq$ & 0.829 \\
\hline Postop $2^{\text {nd }} \mathrm{hr}$ & $1.4 \pm 1.18(1)^{\ddagger}$ & $1.4 \pm 0.91(2)^{\ddagger}$ & 0.914 \\
\hline Postop $4^{\text {th }} \mathrm{hr}$ & $1.13 \pm 0.99(1) \ddagger$ & $1.27 \pm 0.88(1)^{\ddagger}$ & 0.583 \\
\hline Postop $6^{\text {th }} \mathrm{hr}$ & $1.13 \pm 1.13(1) \ddagger$ & $1.07 \pm 0.7(1) \ddagger$ & 0.983 \\
\hline Postop $12^{\text {th }} \mathrm{hr}$ & $0.73 \pm 0.96(0) \ddagger$ & $0.73 \pm 0.59(1) \ddagger$ & 0.634 \\
\hline Postop $24^{\text {th }} \mathrm{hr}$ & $0.47 \pm 0.64(0) \ddagger$ & $0.6 \pm 0.51(1) \ddagger$ & 0.396 \\
\hline
\end{tabular}

Mann-Whitney U Test; †¥Wicoxon Sign Test; ${ }^{*} \mathrm{p}<0.05 ; * * \mathrm{p}<0.01$; twhen evaluating in-group $p<0.05$; $\neq$ when evaluating in-group $p<0.01 ;$ SD: Standard deviation.

TABLE 3. Verbal Descriptor Scale (VDS) Variation

\begin{tabular}{|c|c|c|c|}
\hline VDS & $\begin{array}{c}\text { Group T } \\
\text { Mean } \pm S D \\
\text { (Median) }\end{array}$ & $\begin{array}{c}\text { Group C } \\
\text { Mean } \pm S D \\
\text { (Median) }\end{array}$ & $\mathrm{p}$ \\
\hline Postop $1^{\text {st }} \min$ & $1.33 \pm 0.49(1)$ & $2.53 \pm 0.64$ (3) & $0.001^{* *}$ \\
\hline Postop $5^{\text {th }} \min$ & $1 \pm 0.38(1) \dagger$ & $2.33 \pm 0.72(2)$ & $0.001 * *$ \\
\hline Postop $15^{\text {th }}$ min & $0.93 \pm 0.46(1) \dagger$ & $2.07 \pm 0.96(2) \dagger$ & $0.001 * *$ \\
\hline Postop $30^{\text {th }}$ min & $0.93 \pm 0.46(1) \dagger$ & $1.93 \pm 0.88(2) \dagger$ & $0.001^{* *}$ \\
\hline Postop $1^{\text {st }} \mathrm{hr}$ & $0.93 \pm 0.46(1) \dagger$ & $1.4 \pm 0.74(1) \neq$ & $0.047 *$ \\
\hline Postop $2^{\text {nd }} \mathrm{hr}$ & $0.8 \pm 0.56(1) \ddagger$ & $1.13 \pm 0.64(1)^{\ddagger}$ & 0.140 \\
\hline Postop $4^{\text {th }} \mathrm{hr}$ & $0.73 \pm 0.46(1) \ddagger$ & $0.93 \pm 0.59(1) \ddagger$ & 0.339 \\
\hline Postop $6^{\text {th }} \mathrm{hr}$ & $0.73 \pm 0.59(1)^{\ddagger}$ & $0.8 \pm 0.56(1) \ddagger$ & 0.732 \\
\hline Postop $12^{\text {th }} \mathrm{hr}$ & $0.6 \pm 0.63(1) \neq$ & $0.47 \pm 0.52(0) \neq$ & 0.604 \\
\hline Postop $24^{\text {th }} \mathrm{hr}$ & $0.27 \pm 0.46(0) \ddagger$ & $0.4 \pm 0.51(0) \ddagger$ & 0.446 \\
\hline
\end{tabular}

Mann-Whitney U Test; †¥Wicoxon Sign Test; $* p<0.05 ; * * p<0.01$; twhen evaluating in-group $\mathrm{p}<0.05$; $\neq$ when evaluating in-group $\mathrm{p}<0.01$; SD: Standard deviation.

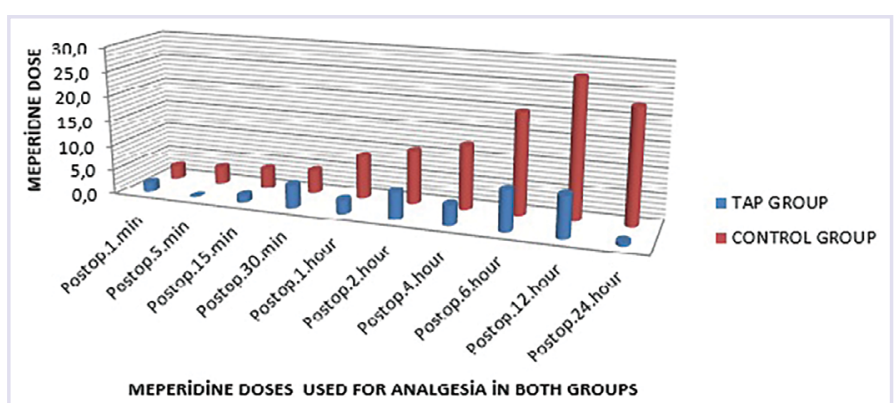

FIGURE 2. The meperidine dose variation between the groups.

a significant decrease in all post-operative measurement times compared to post-operative $1^{\text {st }}$ minute $(p<0.01)$. In group $\mathrm{C}$, according to post-operative $1^{\text {st }}$ minute, there was a significate decrease after $15^{\text {th }}$ minute post-operative measurement times $(p<0.05, p<0.01)$ (Table 3$)$.

The total dose of meperidine that was used in PCA for post-operative analgesia was higher in group $\mathrm{C}$ than group T statistically $(\mathrm{p}=0.001 ; \mathrm{p}<0.01)$ (Fig. 2$)$.

The need for analgesia for the first time was longer in group $T$ than group $S(p=0.003 ; p<0.01)$.

There was no significant difference between groups in breastfeeding and mobilization times, and also there was no significant difference in patient satisfaction and nausea or vomiting ratios.

\section{DISCUSSION}

In this study, we have compared the analgesic effects by performing the USG-TAP block through injecting $0.25 \%$ bupivacaine and $0.9 \% \mathrm{NaCl}, 30 \mathrm{ml}$ each for the left and the right, at a total of $60 \mathrm{ml}$, after a cesarean section performed under general anesthesia. Our study demonstrated that in elective cesarean section performed under general anesthesia with a Pfannenstiel incision, TAP block with $60 \mathrm{~mL} 0.25 \%$ bupivacaine $(30 \mathrm{~mL}$ in each side) could decrease 24 h post-operative pain intensity and analgesic consumption.

The time to the first analgesic requirement was longer in parturients who received the TAP block. The use of meperidine for post-operative analgesia was higher in the control group. There has not been any need for extra analgesia in the TAP group. There was not a significant difference in patient satisfaction in both groups. The pain and discomfort after the cesarean section have a negative effect on early ambulation and breastfeeding, which can result in post-operative complications and the mother's 
discomfort [9] Thus, providing effective and safe postoperative analgesia can prevent these morbidities.

Ripoles et al. [10] found in their multicenter review study that TAP block reduces the need for analgesia and VAS in post-operative 24 hours. In our study, we found similar results that TAP block reduces meperidine consumption and reduces VAS after the cesarean section.

Mcdonnel et al. [11] performed a bilateral TAP block using $1.5 \mathrm{mg} / \mathrm{kg}$ ropivacaine (to a maximal dose of 150 $\mathrm{mg}$ ) or saline on each side at fifty patients after the cesarean section. Patients undergoing TAP block with ropivacaine had reduced $48 \mathrm{~h}$ morphine requirements, and a longer time to first PCA morphine request.

Abdallah et al. [12] found in their multicenter review which consists of five studies and 312 patients that, TAP block constitutes an effective analgesic option for post-operative analgesia after the cesarean section performed under spinal anaesthesia when spinal morphine is not used.

There are varieties between the choice of local anesthetic and constipation, techniques of the TAP block. However, there is not enough evidence which technique or concentration is superior to the other [13].

McMorrow et al. [14] found in their study that spinal morphine (but not TAP block) improved analgesia after the cesarean section. The addition of TAP block with bupivacaine to spinal morphine did not further improve analgesia. Intrathecal morphine has advantages comparing to TAP block, but it also has strong disadvantages post-operative nausea and vomiting (PONV) are some of these complications. At 30\% of the patients who has intrathecal morphine has obvious pruritus. However, respiratory depression is the most serious side effect of intrathecal morphine [15]. In the study in which Kanazi et al. [16] compared TAP block with intrathecal morphine at 57 patients, the findings showed that at $46 \%$ of the patients had PONV and $39 \%$ of them had severe itching which has been treated with medical intervention. Kanzai et al. used $0.2 \mathrm{mg}$ morphine in their study, but none of their patients had respiratory depression.

On the contrary, there are studies that claim that TAP Block provides better analgesia when added to the intratechal morphine. Mirza et al. [17] have chosen TAP block for the supportive analgesic method in cases who are having a cesarean section with spinal anesthesia (bupivacaine $12 \mathrm{mg}$, fentanyl $10 \mu \mathrm{g}$, morphine $200 \mu \mathrm{g}$ ). They found that TAP block provides extra analgesia in all cases postoperative 10-19 hours. They think that providing extra analgesia for such a long time is a consequence of local anesthetic spreading to the paravertebral space.

Epidural anesthesia is still a gold standard technique in post-operative analgesia at the cesarean sections. Yoko Onoshi et al. [18] compared TAP block with epidural anesthesia at 94 patients who had cesarean section with combined spinal-epidural anesthesia. Epidural group morphine $(2 \mathrm{mg}$ ) was administered to the epidural space close to the end of surgery. In TAP group, $20 \mathrm{~mL}$ of either $0.375 \%$ ropivacaine or $0.3 \%$ levobupivacaine was infused to both sides of the transversus abdominis plane after surgery. All patients were placed on patient-controlled i.v. analgesia regimen with morphine after surgery. The median time to the first morphine request was longer $(555$ min vs $215 \mathrm{~min}$ ), and the median cumulative morphine consumption within $24 \mathrm{~h}$ was lower ( $5.3 \mathrm{mg}$ vs $7.7 \mathrm{mg}$ ) in the TAP group than in the control group.

To our knowledge, there is no published case report about local anesthetic toxicity in TAP block. We did not see any sign of local anesthetic toxicity in our patients, too. There are two published liver laceration related to the tap block one of these lacerations occurred in USG guided TAP block $[19,20]$.

There are two published case reports about seizures related to TAP block. The first case seizure thought to be a conclusion of intramuscular injection of local anesthetic. In the second case, the reason was the seconder plasma absorption of the local anesthetic solution. We did not have any of these complications in our study.

\section{CONCLUSION}

As a result, TAPblock is a effective and reliable method, which is accepted in many centers worldwide and reduces the need for post-operative analgesia. Using TAPblock is easy and does not lead to any serious complications. In the future, in cases, where epidural analgesia is restricted TAP block can be an important alternative.

We think that not only with the aid of TAP catheters but also possible development of new block techniques, TAP block will play a significant role in multimodal analgesia management.

Ethics Committee Approval: Fatih Sultan Mehmet Training and Research Hospital Ethics Committee. No: 1707317, 2015-56.

Conflict of Interest: The authors declare no conflict of interest.

Financial Disclosure: The authors declared that this study has received no financial support. 
Authorship Contributions: Concept - HB, AAY, GT, FK, NA; Design - HB, AAY, GT, NA; Supervision - HB, AAY, GT, FK; Materials - HB, AAY, FK, MAS; Data collection and/or processing - HB, AAY, GT, FK, MAS; Analysis and/or interpretation - HB, AAY, GT, NA; Writing - HB, AAY, GT; Critical review - GT, FK, MAS, NA.

\section{REFERENCES}

1. Betrán AP, Merialdi M, Lauer JA, Bing-Shun W, Thomas J, Van Look P, et al. Rates of caesarean section: analysis of global, regional and national estimates. Paediatr Perinat Epidemiol 2007;21:98-113. [CrossRef]

2. Leung A. Postoperative pain management in obstetric anesthesia-new challenges and solutions. J Clin Anesth 2004;16:57-65. [CrossRef]

3. Hirose M, Hara Y, Hosokawa T, Tanaka Y. The effect of postoperative analgesia with continuous epidural bupivacaine after cesarean section on the amount of breast feeding and infant weight gain. Anesth Analg 1996;82:1166-9. [CrossRef]

4. Buvanendran A, Kroin JS. Multimodal analgesia for controlling acute postoperative pain. Curr Opin Anesthesiol 2009;22:588-93. [CrossRef]

5. Bujedo BM, Santos SG, Azpiazu AU, Noriega AR, Salazar DG, Andueza MA. Multimodal Analgesia for the Management of Postoperative Pain 2011;54:29-30.

6. Rafi AN. Abdominal field block: a new approach via the lumbar triangle. Anaesthesia 2001;56:1024-6. [CrossRef]

7. El-Dawlatly AA, Turkistani A, Kettner SC, Machata AM, Delvi MB, Thallaj A et al. Ultrasound-guided transversus abdominis plane block: description of a new technique and comparison with conventional systemic analgesia during laparoscopic cholecystectomy. Br J Anaesth 2009;102:763-7. [CrossRef]

8. Niraj G, Kelkar A, Fox AJ. Oblique sub-costal transversus abdominis plane (TAP) catheters: an alternative to epidural analgesia after upper abdominal surgery. Anaesthesia 2009;64:1137-40. [CrossRef]

9. Krivak TC, Zorn KK. Venous thromboembolism in obstetrics andgynecology. Obstet Gynecol 2007;109:761-77. [CrossRef]

10. Ripollés J, Marmaña Mezquita S, Abad A, Calvo J. [Analgesic efficacy of the ultrasound-guided blockade of the transversus abdominis plane
- a systematic review]. Rev Bras Anestesiol 2015;65:255-80. [CrossRef]

11. McDonnell JG, Curley G, Carney J, Benton A, Costello J, Maharaj $\mathrm{CH}$, et al. The analgesic efficacy of transversus abdominis plane block after cesarean delivery: a randomized controlled trial. Anesth Analg 2008;106:186-91. [CrossRef]

12. Abdallah FW, Halpren SH, Margarido CB. Transversus abdominis plane block for postoperativeanalgesia after Caesarean delivery performed under spinalanaesthesia? A systematic review and meta-analysis. Br J Anaesth 2012;109:679-87. [CrossRef]

13. Young MJ, Gorlin AW, Modest VE, Quraishi SA. Review Article Clinical Implications of the Transversus Abdominis Plane Block in Adults. Anesthesiol Res Pract 2012;19:731645. [CrossRef]

14. McMorrow RC, Ni Mhuircheartaigh RJ, Ahmed KA, Aslani A, Ng SC, Conrick-Martin I, et al. Comparison of transversus abdominis plane block vs spinal morphine for pain relief after Caesarean section. Br J Anaesth 2011;106:706-12. [CrossRef]

15. Chaney MA. Side-effects of intrathecal and epidural opioids. Can J Anaesth 1995;42:891-903. [CrossRef]

16. Kanazi G, Aouad M, Abdallah F, Khatib MI, Adham AM, Harfoush DW, et al. The analgesic efficacy of subarachnoid morphine in comparison with ultrasound-guided transversus abdominis plane block after cesarean delivery: a randomized controlled trial. Anesth Analg 2010;111:475-81. [CrossRef]

17. Mizra F, Carvalho B. Transversus abdominis plane blocks for rescue analgesia following Cesarean delivery: A case series. Can J Anaesth 2013;60:299-303. [CrossRef]

18. Onishi Y, Kato R, Okutomi T, Unno N. Transversus abdominis plane block provides postoperative analgesic effects after cesarean section: Additional analgesia to epidural morphine alone. J Obstet Gynaecol Res 2013;39:1397-405. [CrossRef]

19. Farooq M, Carey M. A case of liver trauma with a blunt regional anesthesia needle while performing transversus abdominis plane block. Reg Anesth Pain Med 2008;33:274-5. [CrossRef]

20. Lancaster P, Chadwick M. Liver trauma secondary to ultrasound-guided transversus abdominis plane block. Br J Anaesth 2010;104:509-10. [CrossRef] 